\title{
Severe Pediatric Acute Respiratory Distress Syndrome Due to Scrub Typhus: Successful Ventilation with Airway Pressure Release Ventilation Mode after Becoming Refractory to Protective Ventilation
}

\author{
Sudha Chandelia, Sarika Jain ${ }^{1}$ \\ Department of Pediatric Critical Care, PGIMER and Dr. Ram Manohar Lohia Hospital, ${ }^{1}$ National Center for Disease Control, New Delhi, India
}

\section{Abstract}

Scrub typhus can affect lungs from mild illness like pneumonitis to a severe illness like acute respiratory distress syndrome (ARDS). Such patients may be very challenging to treat when their hypoxemia becomes severe and refractory to treatment. Main treatment is supportive in terms of mechanical ventilation. In adult ARDS, low tidal volume (TV) ventilation has been recommended, but there is no consensus on most effective ventilation mode in children. We present a case of a 12 -year-old girl who developed severe $\mathrm{ARDS}\left(\mathrm{PO}_{2} / \mathrm{FiO}_{2}\right.$ ratio - 58), refractory to low TV ventilation. There was a rapid improvement in oxygenation on the application of airway pressure release ventilation (APRV) mode within $1 / 2 \mathrm{~h}$. She was successfully ventilated and weaned off the ventilator over 5 days. This case highlights the utility of APRV mode of ventilation as a rescue therapy for severe refractory ARDS in children.

Keywords: Acute respiratory distress syndrome, airway pressure release ventilation, pediatric, scrub typhus

\section{INTRODUCTION}

Acute respiratory distress syndrome (ARDS) is one of the serious complications of scrub typhus infection. It can result in severe hypoxemia refractory to mechanical ventilation. There are few options for mechanical ventilation for such situations such as high frequency oscillation ventilation and extracorporeal membrane oxygenation. The role of airway pressure release ventilation (APRV) mode is not clear, especially in children. In this case report, we describe a young girl who was successfully treated with APRV mode of ventilation after the failure of protective ventilation strategy.

\section{Case Report}

A 12-year-old girl was admitted to our Pediatric Intensive Care Unit due to respiratory distress from pneumonia. In addition, she also had hepatitis and thrombocytopenia. An eschar was seen on her back. Intravenous azithromycin was started on clinical suspicion of scrub typhus. On the $3^{\text {rd }}$ day, she deteriorated and developed hypoxemia. $\mathrm{Her} \mathrm{SpO}_{2}$ was

\begin{tabular}{|l|l|}
\hline \multicolumn{2}{|c|}{ Access this article online } \\
\hline Quick Response Code: & Website: \\
\hline & www.ijccm.org \\
\cline { 2 - 2 } & \\
\hline
\end{tabular}

$86 \%$ on an oxygen flow of $81 /$ min by simple mask. She was started on continuous positive airway pressure (positive end expiratory pressure (PEEP) up to $10 \mathrm{cmH}_{2} \mathrm{O}$ ) but didn't show any improvement. Now, her $\mathrm{PO}_{2} / \mathrm{FiO}_{2}(\mathrm{PF})$ ratio was 58 , more than two quadrants were affected on chest X-ray, had received a PEEP of $10 \mathrm{cmH}_{2} \mathrm{O}$ and echocardiography was normal [Figure 1]. A diagnosis of severe ARDS was made. She also developed shock. She was ventilated with $\mathrm{FiO}_{2}-100 \%$, positive inspiratory pressure (PIP) - 22 mbar, PEEP - 5 mbar, rate $-18 / \mathrm{min}$, and $\mathrm{Ti}-1 \mathrm{~s}$ for persistent hypoxemia and received dopamine with noradrenaline for shock. We had to sedate her for patient-ventilator asynchrony. We had to increase gradually PIP and PEEP to 34 mbar and 17 mbar,

Address for correspondence: Dr. Sudha Chandelia, Room No. 403, Academic Building, Dr. Ram Manohar Lohia Hospital, PGIMER, New Delhi - 110 001, India. E-mail:sudhach83@rediffmail.com

This is an open access article distributed under the terms of the Creative Commons Attribution-NonCommercial-ShareAlike 3.0 License, which allows others to remix, tweak, and build upon the work non-commercially, as long as the author is credited and the new creations are licensed under the identical terms.

For reprints contact: reprints@medknow.com

How to cite this article: Chandelia S, Jain S. Severe pediatric acute respiratory distress syndrome due to scrub typhus: Successful ventilation with airway pressure release ventilation mode after becoming refractory to protective ventilation. Indian J Crit Care Med 2017;21:326-8. 
respectively, but $\mathrm{PO}_{2}$ did not improve. Now, the $\mathrm{SpO}_{2}$ and $\mathrm{PF}$ ratio were $90 \%$ and 61 , respectively. Ventilation monitoring showed a $\mathrm{P}_{\text {peak }}$ : 34-36 mbar; compliance: $14.5-17 \mathrm{ml} / \mathrm{mbar}$; mean airway pressure (MAP): 19 mbar; $\mathrm{P}_{\text {plateau }}: 35$ mbar, and tidal volume (TV): $149-176 \mathrm{ml}(6-7 \mathrm{ml} / \mathrm{kg})$. Reducing the TV further, resulted in lower $\mathrm{SpO}_{2}$ and $\mathrm{pH}$. Increasing PEEP led to worsening in shock. After $18 \mathrm{~h}, \mathrm{PO}_{2}$ dropped to $54 \mathrm{mmHg}$. We changed her ventilation mode to APRV. Lung injury score was 3.5 before starting APRV. Initial settings were $\mathrm{P}_{\text {high }}-26$ mbar, $\mathrm{P}_{\text {low }}-0, \mathrm{~T}_{\text {high }}-4 \mathrm{~s}$, and $\mathrm{T}_{\text {low }}-0.4 \mathrm{~s}$. After $1 / 2 \mathrm{~h}$, the $\mathrm{SpO}_{2}$ increased from $90 \%$ to $94 \%$; and after $1 \mathrm{~h}$, it increased to $97 \%$ with $\mathrm{PO}_{2}$ of $75.6 \mathrm{mmHg}$. The TV, compliance, and MAP increased to $10 \mathrm{ml} / \mathrm{kg}, 26 \mathrm{ml} / \mathrm{mbar}$, and $23 \mathrm{mbar}$, respectively. $\mathrm{P}_{\text {peak }}$ decreased to 28 mbar [Figure 2]. We could reduce $\mathrm{FiO}_{2}$ to $80 \%$. Sedation was stopped as there was no asynchrony. Consistent improvement was observed, and after 3 days, weaning was started by reducing $\mathrm{P}_{\text {high }}$ by 2 and increasing $\mathrm{T}_{\text {high }}$ by 0.5 (drop and stretch technique). Shock also improved, and vasopressor medications were stopped. She showed mild-moderate intercostal retractions when reached at settings of $\mathrm{P}_{\text {high }}-18 \mathrm{mbar}$ and $\mathrm{T}_{\text {high }}-6 \mathrm{~s}$. We stopped the ventilator weaning at this stage and maintained the settings at a little higher levels $\left(\mathrm{P}_{\text {high }}-20\right.$ and $\left.\mathrm{T}_{\text {high }}-6\right)$ for $12 \mathrm{~h}$. Chest X-ray showed complete aeration [Figure 3]. Weaning was again tried, and this time, we could gradually reduce the settings to $\mathrm{P}_{\text {high }}-6$ and $\mathrm{T}_{\text {high }}-10$. She was put on T-piece which she tolerated well without any respiratory distress. After $2 \mathrm{~h}$, she was extubated successfully, kept under observation for $24 \mathrm{~h}$ and shifted to the ward from where she was discharged after 2 days. Meanwhile, her serology showed elevated OX-K titers $(>1: 160)$ suggestive of scrub typhus. She was followed up for 4 months after discharge and showed good health.

\section{Discussion}

Scrub typhus is a rickettsial infection caused by Orientia tsutsugamushi transmitted by larval trombiculid mites. In humans, it often causes multisystem disease. Pulmonary complications include pneumonitis, pleural effusion, and ARDS. ARDS as a complication of scrub typhus is rare. The scant pediatric literature shows that $1.1 \%-9.3 \%$ children with scrub typhus may develop ARDS. ${ }^{[1,2]}$ Adult literature shows that its incidence is more in patients who are diagnosed late ${ }^{[3]}$ Organ damage in scrub typhus is due to microvascular endothelium damage resulting in vasculitis, perivasculitis, and increased microvascular permeability. ${ }^{[4]}$ The role of immune mechanism without vasculitis is also likely as shown in lung biopsy reported by Park et al ${ }^{[5]}$ Our patient was affected severely and became refractory to low TV ventilation. It showed rapid and sustained improvement in oxygenation on the application of APRV mode of ventilation. APRV increases oxygenation by giving a continuous high pressure $\left(\mathrm{P}_{\text {high }}\right)$ to maintain MAP and thus resulting in alveolar recruitment. ${ }^{[6]}$ This pressure is released for very brief time to facilitate tidal ventilation $\left(\mathrm{T}_{\text {low }}\right)$. Asynchrony was less as the patient could breathe spontaneously throughout ventilator breath. This resulted in less or no sedation and

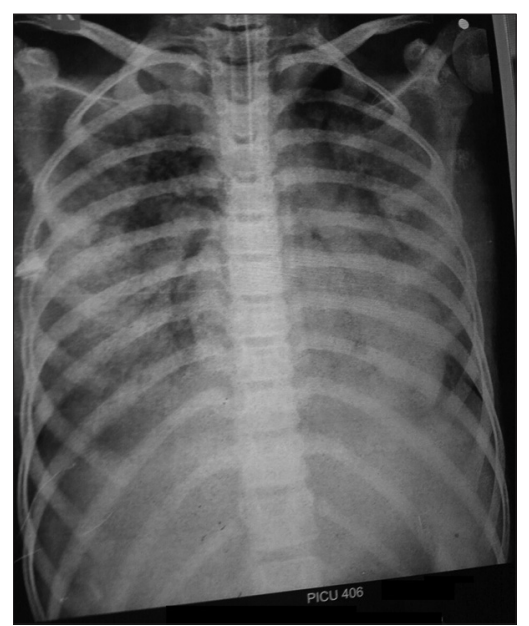

Figure 1: Chest X-ray showing more than two lung quadrants affected used for lung injury score

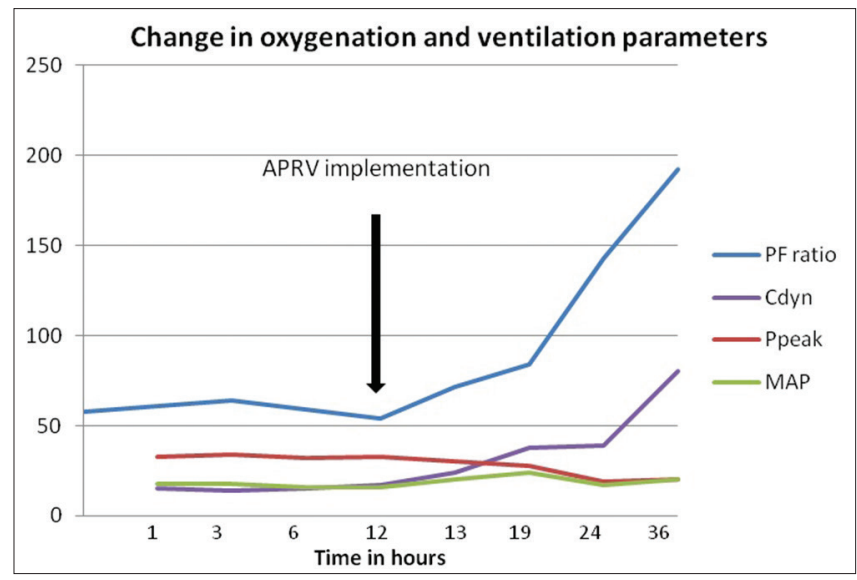

Figure 2: Graph showing better oxygenation and ventilation parameters after implementation of airway pressure release ventilation mode in same patient

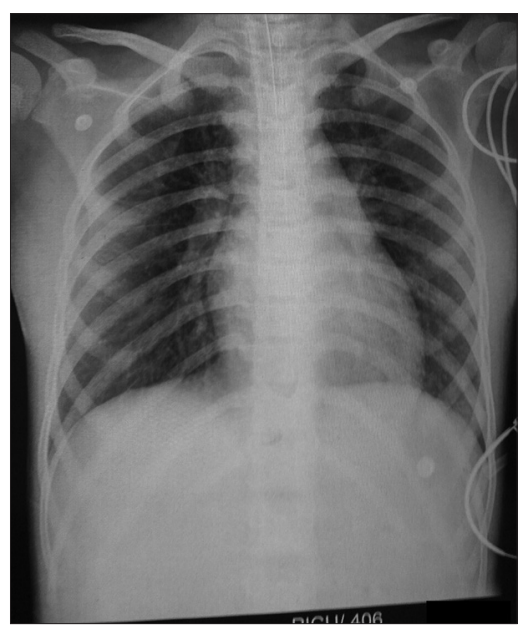

Figure 3: Chest X-ray showing complete aeration of the lungs after implementation of airway pressure release ventilation mode

muscle relaxant use. Moreover, patient self-breathing leads to preservation of respiratory muscles and ventilation of 
dependent lung areas reducing V/Q mismatch. It limits peak pressure and increases compliance. ${ }^{[7]}$ We observed that shock state did not worsen with APRV rather it improved, and vasopressors could be tapered in $48 \mathrm{~h}$. It has been postulated that abdominal pressure is increased, and pleural pressure is decreased during spontaneous breathing (when on APRV) which encourages venous return. Another very important observation from animal studies is that APRV may reduce the risk of ventilator-induced lung injury and so may be more protective than other modes of ventilation. ${ }^{[8]}$ In this case, APRV mode of ventilation was the game changer. APRV mode resulted in survival of the patient with a good mental and physical outcome. This case is unique for two reasons: one, scrub typhus is a rare cause of ARDS in children, and the other, there is a limited experience on the role of APRV mode in severe ARDS in children. To conclude, APRV mode is an effective ventilation strategy to improve oxygenation rapidly in pediatric patients with severe ARDS. It can be used as a rescue therapy in severe ARDS when it becomes refractory to conventional low tidal volume ventilation.

\section{Financial support and sponsorship}

Nil.

\section{Conflicts of interest}

There are no conflicts of interest.

\section{REFERENCES}

1. Gupta P, Gurjar U, Sharma BS, Gupta ML. Complication profile of scrub typhus and its association with total leucocyte count. Int J Contemp Pediatr 2017;4:96-9.

2. Thomas R, Puranik P, Kalal B, Britto C, Kamalesh S, Rego S, et al. Five-year analysis of rickettsial fevers in children in South India: Clinical manifestations and complications. J Infect Dev Ctries 2016;10:657-61.

3. Wang CC, Liu SF, Liu JW, Chung YH, Su MC, Lin MC. Acute respiratory distress syndrome in scrub typhus. Am J Trop Med Hyg 2007;76:1148-52.

4. Walker DH. Rickettsiae and rickettsial infections: The current state of knowledge. Clin Infect Dis 2007;45 Suppl 1:S39-44.

5. Park JS, Jee YK, Lee KY, Kim KY, Myong NH, Seo PW. Acute respiratory distress syndrome associated with scrub typhus: Diffuse alveolar damage without pulmonary vasculitis. J Korean Med Sci 2000;15:343-5.

6. Kollisch-Singule M, Emr B, Smith B, Ruiz C, Roy S, Meng Q, et al. Airway pressure release ventilation reduces conducting airway micro-strain in lung injury. J Am Coll Surg 2014;219:968-76.

7. Roy S, Habashi N, Sadowitz B, Andrews P, Ge L, Wang G, et al. Early airway pressure release ventilation prevents ARDS-a novel preventive approach to lung injury. Shock 2013;39:28-38.

8. Emr B, Gatto LA, Roy S, Satalin J, Ghosh A, Snyder K, et al. Airway pressure release ventilation prevents ventilator-induced lung injury in normal lungs. JAMA Surg 2013;148:1005-12. 